2015-09-21

\title{
What role do teaching mentors play in supporting new university lecturers to develop their teaching practices?
}

\section{Turner, Rebecca}

http://hdl.handle.net/10026.1/4285

\subsection{0/19415257.2015.1065898}

Professional Development in Education

Informa UK Limited

All content in PEARL is protected by copyright law. Author manuscripts are made available in accordance with publisher policies. Please cite only the published version using the details provided on the item record or document. In the absence of an open licence (e.g. Creative Commons), permissions for further reuse of content should be sought from the publisher or author. 
1 What role do teaching mentors play in supporting new university lecturers to develop their teaching practices?

3 Rebecca Turner $^{1 *}$, Rong Huang ${ }^{2}$, Oxana Poverjuc ${ }^{1}$ \& Lynne Wyness ${ }^{1}$

$4 \quad{ }^{1}$ Pedagogic Research Institute and Observatory, Plymouth University, Drake Circus, 5 Plymouth. PL4 8AA.

$6 \quad{ }^{2}$ School of Tourism and Hospitality, Plymouth University, Drake Circus, Plymouth. PL4 8AA.

$8 \quad$ Corresponding author rebecca.turner@plymouth.ac.uk

9

\begin{abstract}
We examine the support mentors provide to new lecturers as part of a postgraduate programme designed to familiarise them with university teaching. Drawing on qualitative data collected from 13 new lecturers and nine mentors, we document the support new lecturers' call upon to shape their practice. We identify important issues surrounding the significance of mentor choice, both in terms of a mentor's experience, position and knowledge of their role, which determine the effectiveness of professional learning. Difficult issues were observed relating to prioritisation and workload for new lecturers and their mentors, and as a consequence the wider networks of colleagues and peers new lecturers drew upon were seen as an essential source of advice. Indeed, the extent of their use depending on assistance available from mentors. Our data indicate the need for careful framing of mentoring relationships in terms of professional development and teaching enhancement to ensure the benefits of these interactions are realised. Equally both parties need to be encouraged to use reflection to scaffold interactions to promote professional learning. Our data also identify the need for recognition for those performing mentoring roles, to ensure they can dedicate necessary time so that productive relationships are sustained for the duration over which support is required.
\end{abstract}

Keywords: Higher Education; Professional Development; Professional Learning; Informal learning, Reflection

\title{
Introduction
}


31 Internationally there has been a proliferation of courses that seek to professionalise the practice of being a university teacher (Kandlbinder and Peseta 2009). The primary focus of this provision is teaching and learning, preparing lecturers to address issues relating to student support, quality assurance, assessment, session and programme design as well as offering feedback on emerging practice (Parson et al., 2012). Studies of these programmes have identified common features including theoretical underpinnings (Kahn et al., 2008), intended outcomes (Bamber 2008) and participants' experiences (Warhurst, 2006). These studies have demonstrated the role of these courses in supporting new lecturers to adapt to the role of being a university lecturer, as in addition to introducing theory and practice, they induct them into the practice of teaching and supporting student learning in their new institutional context, and integrate them into a community that works to support teaching and learning (Smith, 2010; Warhusrt, 2006).

One aspect of these programmes that has received limited attention has been the role of teaching mentors. These represent a named individual often located in the department or school in which a new lecturer is based who provides guidance around issues related to teaching. Mentors can contextualise the generic or theoretical aspects of teaching preparation programmes to the perspectives of participants' discipline (Gosling, 2009; Knight \& Trowler, 1999). They can also be a source of advice around daily practices and procedures, as well as offering feedback on teaching and other issues that may arise (Adcroft \& Taylor, 2009). For new lecturers, having a named person to guide them is seen as an invaluable source of support as they adapt to a challenging and demanding role (Barkham, 2005). Therefore, in relation to the volume of research relating to teaching preparation programmes, it is perhaps surprising to note the limited attention teaching mentors have received. Contemporary research tends to concentrate on the perspectives of either the mentor or mentee (e.g. Adcroft and Taylor, 2009; Barkham, 2005; Donnelly and McSweeney, 2010) and they are often conducted with limited consideration of the wider support (e.g. colleagues, course peers) new lecturers may draw upon to frame their emerging practice. 
63 In this paper we draw on data gathered as part of a study that followed 13 new lecturers, and their mentors, through their first year of university teaching. We provide insights into the role the mentor plays in supporting new lecturers. We also reflect on the importance of the mentor's experience in undertaking this role, and highlight important issues regarding the support, preparation and recognition that mentors receive.

\section{Professionalising university teaching in England}

Enhancing the practice of university teaching and supporting student learning is an established feature of the landscape of higher education (HE). In the UK organisations such as the Staff and Educational Development Association and the Association of University Teachers championed the importance of professional development for those involved in teaching and supporting students (Wisdom et al., 2013). These organisations provided staff development, guidance and an accreditation framework for those engaged in training courses to prepare for university teaching. They were also instrumental in creating the UK Professional Standards Framework (HEA, 2011) which is used to guide the practice of university teaching (Wisdom et al., 2013).

Whilst driving forward a clear agenda to professionalise the practice of university teaching, engagement with teaching preparation courses and staff development was variable, depending often on the focus of institutions (i.e. the extent to which they placed an emphasis on teaching and / or research) (Parson et al., 2012). Due to significant changes in the funding of $\mathrm{HE}$, diversification of the student populations and increasing government intervention, teaching and learning has become highly politicised (Gibbs, 2010). Through mechanisms such as the National Students Survey students can publicly comment on the perceived quality of their university experience, in particularly rating their experiences of teaching, learning and assessment; the results of this survey are perceived by some as instrumental in the decisions students make in selecting their choice of university (Kovacs et al., 2010). Following the Browne Review (2010) a focus was also placed upon the training providing to 
university staff, with a requirement for universities to report on the number of staff possessing a teaching qualification that has prepared them for university teaching. This has resulted in a change in attitudes toward teaching preparation for new lecturers, with growing expectations for new lecturers to participate in some form of training as part of their probationary commitment (Gosling, 2010; Parsons et al., 2012).

Implicit in this drive is the assumption that by training new lecturers, and aligning their knowledge of teaching and learning to the UKPSF, will enhance the quality of teaching and learning, a concern of policymakers for a number of years (Turner et al., 2013; Gosling, 2009). This is not an assumption we will directly consider here, however, with respect to the wider framing of this study we feel it is an important position to acknowledge, as many of the participants on teaching preparation courses, as well as those working to promote university teaching, are aware of the contentious nature of this assumption and the implications it has on the expectations for university teaching (Gibbs, 2010; Quinn 2012). However, England is not alone in pushing forward an agenda for enhancing university teaching, similar moves towards providing training for new lecturers, professional development for established lectures and examining student feedback have taken place across Europe, North America, New Zealand and Australia (Kandlbinder and Peseta 2009; Parson et al., 2012).

\section{Professional learning in the workplace}

Entry into a new workplace stimulates a period of professional learning, which can take place through a series of formal and informal interactions (Eraut, 2004; 2007; Knight et al. 2006). Formal learning entails pre-determined outcomes and taught sessions; by contrast, informal learning is a hidden process that results from unstructured or opportunistic interactions and experiences, and is associated with tacit knowledge (Eraut, 2004; Knight et al., 2006). This aligns with the idea of the distributed apprenticeship element of professional learning, whereby a range of individuals (e.g. colleagues, peers, trainers) stimulate professional learning, through deliberative, reactive and implicit actions (Eraut, 2004). Much professional learning 
125 is informal and occurs as a consequence of an individual performing their role and 126 interacting with colleagues (Eraut, 2004). Therefore in many instances newcomers 127 are not explicitly aware of learning about their role, rather they express a sense of 128 feeling more comfortable in what they are doing or of growing in confidence (Eraut, 129 2004; Knight et al., 2006). This demonstrates the situated nature of professional 130 learning, where activities such as conversations make significant contributions to 131 newcomers' understandings of the workplace (Haigh, 2005). In many instances such 132 learning is unplanned and $a d$ hoc, and the quality of professional learning that takes 133 place is highly variable.

In relation to these informal mechanisms of professional learning, mentoring blurs the 136 boundaries of formal and informal learning (Eraut, 2007). Mentoring is widely used 137 to familiarise newcomers to the workplace and support them in developing technical, 138 interpersonal and political skills and competences essential to their role (Hudson, 139 2013; Ehrich et al., 2004; Ragins and Cotton, 1999). Researchers (e.g. Kram, 1983; 140 Hobson et al., 2009; Noe, 1988) have identified mentors as having specific career 141 development and psychosocial functions, as explored through Kram's (1983) Mentor

142 Role Theory. These career development functions involve actions such as 143 sponsorship, advocacy, coaching, protection, providing challenging assignments and 144 offering exposure (Kram, 1983). As a newcomer's position in an organisation 145 changes, and they realise their potential, the requirements on a mentor changes (Kram, 146 1983; Gehrke, 1988). An assumption underpinning the role of a mentor is that they 147 themselves are in a role that allows them to perform these functions, and also have the 148 knowledge, skills and experience on which to draw to support a junior colleague 149 (Kram, 1983).

151 Mentoring may involve a structured programme of support through which goals are 152 set, shaping interactions and monitoring progress, usually through a series of regular 153 meetings (Donnelly and McSweeny 2010). In these instances the mentor usually 154 gains recognition for the support they offer. Informal mentoring relationships are less 155 structured with limited recognition of the process and outcomes (Ehrich et al., 2004; 156 Ewing et al., 2008). Regardless of the approach, mentoring is recognised as having a 
number of benefits for both the newcomer and the mentor (Ragins and Cotton, 1999). For the mentee, it can create a sense of collegiality and belonging that promotes understanding of a new workplace (Donnelly and McSweeney 2010). Studies of mentors' experiences note that mentoring creates situations for reciprocal learning since, by supporting a new colleague, mentors can engage with self-reflection, stimulating their own professional learning (Barkham, 2005; Kamvounias et al., 2008). Overall, effective mentoring relationships have been identified as increasing staff retention, job satisfaction and career progression (Ehrich et al., 2004; Ragins and Cotton, 1999).

Research into professional learning and mentoring has led to the idea of 'relationship constellations' (e.g. Higgins and Kram, 2001: 264); these represent the range of individuals who may provide developmental support through an individual's career, in addition to that traditionally provided by a mentor. This reflects the portfolio nature of individual careers and the shift in focus to development taking place on an on-going basis throughout an individual's professional life (Higgins and Kram, 2001). Nowadays 'mentoring' may be provided through formal, e.g. organisational structures associated with induction or progression through the workplace, or informally, through support offered by colleagues to one-another. In these instances individuals stimulate or promote the professional learning of colleagues with a view to supporting their establishment, and or progression, in the workplace.

A portfolio career typifies the early career trajectory of academics, who usually gain a lecturing position after completing a period of research training and post doctoral work, therefore they commonly bring with them an established network of researchers and former colleagues (Archer, 2008). Through a teaching qualification they may be introduced to a new community of peers, as documented in studies by researchers such as Smith (2010) and Warhurst (2006), as well as provided with a teaching mentor. With respect to teaching qualifications for new lecturers, teaching mentors have an important role to play in contextualising the general, theoretical and practicebased principles of these programmes. Knight and Trowler (1999) highlighted the importance of mentors in providing an individualised experience, particularly when 
they are located in the environment in which professional learning will occur (i.e.) new lecturers' home departments. Mentors assist in decoding the systems and structures that underpin new lecturers' roles (Adcroft and Taylor, 2009). From this perspective, mentoring assists in the management of the multiple demands placed on new lecturers and, therefore, it is reasonable to envisage mentors as integral in supporting them to adapt to their role.

The contribution that mentoring is perceived to make to taught programmes for new lecturers is less well documented. In relation to the highly organised nature of these programmes (Bamber, 2008), mentoring relationships appear to be less formalised and new lecturers' experiences of mentoring are reported as variable (Kamvounias et al., 2008; Remmik et al., 2011). Combinations of formal and informal approaches are used, with a tendency for the informal approach to prevail. Whilst a mentor may be committed to supporting a new lecturer, they may receive limited recognition or time to do so; in such situations there is a danger that mentoring can be an additional burden, threatening to undermine the potential development that could be achieved.

\section{Methodology}

\section{Research aims}

Teaching is recognised as a context-specific profession (Trigwell and Prosser, 1996) shaped by the experiences and values a lecturer possesses; however, these are rarely acknowledged in the preparation that new lecturers receive on commencing their role. Nor does this preparation readily acknowledge the diverse professional and cultural profiles of the academic workforce. The research we report here is part of a wider study (Turner et al., 2012) that examined how lecturers negotiated their existing knowledge and experiences of teaching and learning / university life with those they were introduced to through the postgraduate teaching qualification and the wider University's values and ethos around teaching and learning. Existing research on both professional learning (e.g. Eraut, 2004; Knight et al., 2006) and postgraduate teaching qualifications (e.g. Boud and Brew, 2012; Reintes and Kichin, 2014; Warhurst, 2006) identify the importance of mentors, departmental colleagues and 
peers from established / new networks in supporting newcomers to develop the professional knowledge and confidence required to perform their role. Therefore, to examine how new lecturers reconciled or integrated their existing knowledge and experience with the requirements of their new role and workplace, we recognised the importance of considering the networks, both those initiated through the teaching qualification (e.g. mentors and tutors) and those drawn upon by the new lecturers (e.g. course peers, new colleagues and established networks) to support them in their first year of teaching. Here we present this aspect of the study, however, full details of the research methods are giving in order to contextualise the work that was undertaken.

\section{The research setting}

The research was based in a so-called 'new' (post-1992) university in the UK.

Completion of a postgraduate certificate in teaching and learning is tied to probationary requirements; lecturers with less than three years full-time teaching experience are required to complete the programme. As noted above, compulsory professional development for new lecturers in increasingly commonplace, giving lecturers little opportunity to shape or direct the initial training they receive to prepare them for lecturing (Parsons et al., 2012). The course begins by providing a general introduction to the practices of teaching, supporting and assessing students. A series of elective modules provides space for greater consideration of agendas relevant to contemporary HE e.g. employability. The programme can be completed within 12 months, and following this lecturers are recognised as Fellows of the HEA.

During the programme lecturers are allocated a tutor from the course team, required to identify a mentor and encouraged to discuss their experiences with colleagues and peers. Course tutors and mentors have clearly defined roles; tutors observe the new lecturers and provide feedback, assess their written work and offer 'generic' advice on teaching, learning and supporting students. Teaching mentors are integral in supporting lecturers in contextualising pedagogic theory and practice to the disciplinary communities in which they operate. Therefore mentors can be drawn 
from across the University. The mentor also undertakes a teaching review and offers local support on teaching related issues.

New lecturers select their mentor independently, although the course team recommend they choose someone who has either recently completed the programme or an advocate for teaching in their school. Mentors received guidance on their role which includes; meetings to discuss progress on the programme, sharing ideas and acting as a critical friend, undertaking a teaching observation, promoting participation in developmental events and integrating their mentee into their school. The teaching team allow the mentor and mentee to develop their own ways of working and, in this respect the model of mentoring promoted would be classed as informal (Donnelly and McSweeney, 2010). Although the teaching team advocate the importance of these mentoring relationships they are not in a position to offer recognition or reward to mentors. Based on the literature used to examine the role of mentoring in professional learning, there are potential limitations to newcomers selecting their mentor and taking an informal approach to the mentoring relationship (Adcroft and Taylor, 2009). The ability of a mentor to performing functions such as advocacy and protection, and ensuring time is dedicated to ensure a productive mentoring relationship develop is not explicitly considered in this approach. Indeed these are all issues pertinent to the outcomes of this work.

\section{Recruitment}

272 A purposeful sample of 13 participants was selected from those starting the 273 programme in September 2011. Previous studies (e.g. Boyd and Harris, 2010; Green 274 and Maytt, 2011) acknowledged the diverse professional profiles of new lecturers. As a result, the knowledge, experience and expectations they bring to university teaching can be varied. Participants were selected to encompass this diversity, with invitations made based on participants' country of origin and professional / research backgrounds, and more widely to be representative of the cohort as a whole with respect to gender and disciplinary areas (see Table 1). In order to gain an insight into the context (e.g. department and disciplines) in which the new lecturers were working and also support 
they received, their teaching mentors were invited to participate; nine agreed to contribute with others declining due to commitments during the scheduled period of data collection. Details of mentors are presented in Table 2.

[Place Table 1 here]

[Place Table 2 here]

\section{Data collection}

Qualitative data were collected using a combination of methods over the duration of the whole research project, including the data reported here. Data from new lecturers were collected at two points in the academic year; firstly following the induction period of the taught programme then at the end of the teaching year. The initial phase of data collection was split into a one-hour teaching observation, completed using a semi-structured observation protocol, and an in-depth interview. This approach captured espoused reflections on practice and actions taken in practice. The observation protocol was informed by Kreber's (1999) Scholarship of Teaching model. Kreber (1999) states that in learning about teaching, individuals engage in content, process and premise reflections in the three domains of teaching knowledge, which are instructional, pedagogical and curricular. The protocol was designed to capture actions which may be indicative of these domains of knowledge and forms of reflection, as well as general information regarding the teaching session (e.g. format of the teaching session, class size). A provisional analysis of the observation protocols was used as the basis of a stimulated-recall interview (Calderhead, 1981).

\section{At stage two the new lecturers were asked to bring a critical incident from the} reflective logs kept as part of the programme to be discussed during the second interview. The use of critical incidents in this way was informed by Tripp (1993) and, once again, sought to examine their knowledge of teaching. Following discussion of the critical incident, questions were asked regarding their practice, support they 
received, with prompts from stage one to stimulate reflections on how this had changed and developed.

Data were gathered from the mentors half way through the academic year. This timeframe was selected as it followed submission of the first assignment and was rationalised as to have been a time when mentors may have been called upon to support new lecturers in reaching this deadline. Through a semi-structured interview with mentors we gained further insights into the emerging practice of the new lecturers, a background to the teaching practices of participant's schools, school support for participants and their experiences of mentoring. It is this data, along with the responses drawn from the new lecturers regarding the support they drew upon over the academic year, which we report here. Provisional findings from the wider study have been reported in Turner et al., (2012).

\section{Data analysis}

All interview data were audio-recorded and transcribed verbatim. Content analysis was employed to "mak[e] inferences by objectively and systematically identifying specified characteristics of messages" (Holsti, 1969:14). The analysis heeded the research aims, however, in the context of support networks drawn upon and interactions with mentors, we paid particularly attention to the interactions that took place and how these evolved. We were also mindful of Kreber's (1999) categories, specifically those relating to that ways in which individuals reflect on their teaching. These were considered when analysing the accounts of conversations around teaching and learning that took place between the mentors and mentees were examined (i.e. were they focused on discussing the content, process or premise relating to their practice). Following the analyses these themes emerged across both data sets:

- Mentor choice;

- Shaping expectations;

- Promoting professional learning through reflection;

- Pressures and tensions; 
342 In the next section, we will examine each of these themes in turn to uncover the 343 nature of the mentoring relationships, the support networks used and how these 344 changed over the year.

\section{Findings}

\section{Choosing a mentor}

The new lecturers had been University employees for varying timescales. A few had arrived toward the end of the previous academic year; however, most had arrived immediately prior to the start of the taught programme. Therefore, the extent to which they knew their colleagues varied, with implications for their mentor choice. This was also shaped by the new lecturers' intentions and aspirations for the mentoring relationship. Given the explicit links between the mentor and the teaching programme, most participants selected mentors in line with the role prescribed by the teaching team (i.e. someone who had either completed the course recently or were recognised as experienced teachers):

Two new lecturers were allocated a mentor by someone else, which may imply that the school recognised that they may need assistance in knowing from whom to seek support.

Although these rationales appear reasonable, each had implications for the mentoring relationships and patterns of interaction. Those who selected recent completers of the teaching programme tended to approach them to primarily seek advice on the module choice, assignments and programme-related concerns. In contrast those who 
opted for established colleagues tended to engage in discussions around wider teaching practices and school procedures beginning to engage with what Kreber (1999) would identify as curricular knowledge (i.e. developing an awareness of how their teaching connected to the wider curriculum):

'[...] my mentor has a lot of experience, so she's got quite a good few connections [...] for example I haven't done a lot around marking assignments so she's set up a session where we can go and learn a bit about that and observe some [names assessment format]'. Lecturer 6

Whilst these interactions addressed the concerns new lecturers experienced, the relationships that developed varied, which may be attributable to the differing roles the mentors performed. Recent completers perceived themselves familiar with the challenges of being a new lecturer and the teaching programme. They were keen to provide an empathic ear, but they were aware of their own limitations:

'I'm a year and a half into my post here and I very much had to learn by doing and doing things wrong sometimes.' Mentor 8

As this quotation suggests, the extent to which recent completers could socialise their mentee into their school depended on the level to which they themselves were integrated. But equally, as Eraut (2004) cautions, whilst established colleagues would be integrated, their working practices might have become habitual so they may no longer be aware of what a newcomer needed to know. This was evidenced by established mentors' responses to questioning during interviews regarding the pedagogical theories and practice associated with their schools - many struggled to initially name any. Yet this appeared not to be a significant concern of their mentees, as they tended to use their mentors to inform their teaching practices more generally rather than to address queries relating to the teaching programme or seeking to stimulate reflections on their emerging practice that may connect to pedagogical or instructional knowledge (Kreber, 1999).

\section{Shaping expectations}


398 Findings suggest that both parties accepted their role uncritically, with mentors' actions largely informed by their position (i.e. recent completer or established lecturer). It was not evident whether mentors and new lecturers discussed their role or established goals to structure their relationship. Instead an informal approach was adopted, in line with the recommendations of the teaching team, leading to variable mentoring relationships developing. They ranged from mentors and mentees working collaboratively in what they viewed as productive relationships, to those where the mentor was removed from the process with the implicit expectation that the mentee would be in touch if necessary:

Given the multiple pressures lecturers face (Smith, 2010), being 'left to get on with it' (Mentor 9), may not be unexpected, and indeed could be a consequence of the perceived responsibility mentors attributed to the taught programme for supporting new lecturers:

These perceptions could have implications for the quality of, and potential for, professional learning, particularly when these interactions are considered in light of the situated nature of academic development (Boud, 1999). For the new lecturer, connections need to be made between the formal learning of the taught programme and, more generally, through interactions with colleagues, students and the process of doing their job. Mentors are integral to formulating these connections and 
contextualising learning to new lecturers' disciplines and schools. However, the perceived value of mentoring held by mentors could constrain the extent to which meaningful learning occurs.

Comparing the established lecturers with the recent completers it appeared that initially it was the experienced lecturers who appeared to struggle with being mentors, tending to take a step back, perhaps concerned about the workload implications of supporting a colleague. This contrasts the position of the recent completers who were able to recall the extent to which they benefitted from the support of a mentor. As Mentor 1 indicates, once engaged in the process, established lecturers began to appreciate the benefits to the new lecturer and also began to consider how forums (e.g. working groups/programme meetings) to discuss teaching could represent informal learning opportunities for new lecturers:

'So I mean that I suppose in terms of pedagogy, we had a working party and we spent a lot of time thinking about it so I would say about half the department would be involved in it, so we did spend a lot of time thinking about how we might improve that first year for our students and of course [names mentee] been crucially involved in this process.' Mentor 5

These examples provide an insight into the pedagogical workings of schools and demonstrate how informal opportunities for professional learning emerge which allows new lecturers to begin to integrate theoretical knowledge (instructional knowledge) with disciplinary-specific perspectives (instructional or curricular knowledge) (Trowler and Cooper, 2002). They also represent incidences where reflections were stimulated that allowed the new lecturers to explore or develop their pedagogical knowledge (Kreber, 1999). Such interactions have been noted by researchers (e.g. Remmik et al. 2011; Warhurst 2008) as representing valuable opportunities to share their own experiences and perspectives with their colleagues, further promoting the integration of new lecturers into their school as they gain a sense of making a contribution. As Mentor 5 indicates, these interactions were common-place, and therefore mentors need to be made aware of the regularity at which professional learning can occur as part of the preparation they are given prior to taking on this role. 
463 Reflection is integral to the process of mentoring (Barkham, 2005; Gosling, 2009).

464 School-based studies of mentoring have identified both the critical examination of a

465 new teachers practice and their thinking about practice as essential in developing a

466 sense of being an accomplished teacher (Hagger and MacIntyre, 2006). Mentors, who

467 may be perceived as expert teachers, play a fundamental role in this process by

468 assisting a new teacher comprehend what 'good' teaching represents (Gosling, 2009;

469 Langdon, 2011). However, these studies have reported that mentors face challenges

470 in supporting new teachers in undergoing this development and engaging with

471 effective reflective practices (Langdon, 2011). If this is the situation in school-based

472 teacher development, then it is perhaps not surprising in this study that we found the

473 limited extent to which reflective practice underpinned mentoring interactions. With

474 respect to the development of university-based teachers, Trowler and Cooper (2002)

475 noted disciplinary differences in relation to an individual's predisposition to reflection,

476 with those from the sciences in particular struggling with this activity. Given that

477 seven of our participants were drawn from these disciplines this could account for this

478 situation. The primary source of reflection was the teaching observation mentors

479 completed as part of the teaching programme. Commonly discussions between

480 mentors and the new lecturers tended to be functional, concentrating either on

481 effective practice (i.e. what works) or providing advice and information either deemed

482 essential by the mentor or in response to a mentees request:

483

484

485

486

487

488

489

490

491
'I was concerned about my accent, the local students would not be able to understand my accent, the feedbacks that I got from [my] mentor, said it's fine, you can understand everything.' Lecturer 4

'I suppose the most important one of all is kind of informal discussions that we would have about our own practice and things that went wrong or things that worked well and so on, so I think that's a big part that sometimes we don't acknowledge the importance of that enough.' Mentor 7

Whilst it is important for the mentee to be able to access information central to their practice, the emphasis from new lecturers requesting, and mentors providing, 
functional information can lead to a focus on prescriptive rather than innovative practice. This has been observed as a limitation in the use of reflection to support the development of lecturers teaching practice (e.g. Gosling, 2009; Hammersley-Fletcher and Orsmond, 2005). Such interactions are described as indicating a 'reductive' approach to mentoring resulting from its narrow conceptualisation (e.g. Achinstein and Athanases, 2006). In the context of our study, this approach may have also emerged due to the patterns of interactions between the new lecturer and the mentor, and a perceived lack of time in the department that lecturers can dedicate to reflection: 'There's not an awful lot of time for reflection [...]. We build meetings into the system - on Wednesday afternoons we'll have this meeting, that meeting. I think it would be more useful if there was some more sort of structured reflection for teaching activities.' Mentor 2

'I can remember in the past when we decided to make changes in the programmes and spent a year talking about what the changes would be, everybody was involved in those discussions, everybody was passionate about carrying those changes forward. And I don't know where that debate happens any longer, because there just isn't the time for it.' Mentor 1

\section{As these mentors acknowledge, time is pressured. The new lecturers' primary} concerns were with doing a good job, completing the teaching programme, and surviving the year. They demonstrated limited capacity for reflecting on practice and therefore this is a role mentors should encourage, particularly in the early stages of the mentoring relationship when lecturers may be overwhelmed with the demands placed upon them. As advocated by Gosling (2009), mentors could request mentees bring 'critical incidents' or examples from their practice that could provide a stimulus for further discussion and reflection in their meetings. This may also serve to move the mentee beyond focusing solely on practical challenges or immediate concerns by encouraging a wider appreciation of the contribution that reflection can make to enhancing teaching practice.

\section{Pressures and tensions}


523 The first few years of lecturing are challenging and, although this is well-documented

524 (e.g. Smith 2010), we feel it is important to reframe these challenges in relation to

525 mentoring. The new lecturers documented the challenges they experienced (e.g.

526 concerns with workload; designing modules; balancing research, teaching and

527 institutional ways of working) and whilst these may have been the source of

528 considerable personal frustration and pressure, they do represent the challenges

529 experienced by all new lecturers (Smith, 2010; Warhurst, 2006). Mentors were

530 acutely aware of, and empathised with, the challenges faced:

531

532

533

534

535

536

537

538

539

540

541

542

543

544

545

546

547

548

549

550

551

552

553

'A fair teaching load, in order to settle into teaching do [names course], start establishing yourself as research active [...] there's just a lot and everything is urgent.' Mentor 10

'I think the main point I got from her was that she felt she was being pulled in lots of directions she wanted to continue her research and she had to think about her teaching.' Mentor 8

However, there was a sense of powerlessness from mentors around the extent to which they could assist their mentees in resolving their challenges. This could partly be related to the role the mentors adopted, in that most saw themselves as primarily offering guidance relating to teaching and felt that it was beyond their remit to address wider concerns:

'And I just thought new members of staff needed more support than that, but I wasn't in a position to be able to say that shouldn't happen because ultimately, the Head of School decides workloads.' Mentor 2

This sense of powerlessness could also depend on the extent to which mentors were familiar with the working practices of their school and also their role power.

Interestingly, two new lecturers selected mentors from outside their school. Whilst this may provide greater opportunities for networking, as with the recent completers, these mentors might have not have been in a position to respond to functional questions regarding procedures in their mentees' school. Thus, proximity may also be a factor in mentor choice. Similarly, a mentor who is a recent completer or from another school may not be in a position to act as an advocate or support their mentee in reconciling challenges. 
555 Either one, or a combination, of these positions could lead to the mentor experiencing

556 a sense of powerlessness in relation to the support they could provide, with wider

557 implications for how the role of a mentor is perceived. Mentors are required to

558 possess skills such as the ability to be an advocate and act as a role model,

559 demonstrating confidence and efficacy as a professional (Donnelly and McSweeney,

560 2010; Kram, 1983). However, if the mentor does not feel they can support their

561 mentee through challenging times, or address practical concerns, it could undermine

562 their relationship. If this happens at the formative stages of their relationship it may

563 hinder potential for professional learning through mentoring, which would require

564 new lecturers to seek alternative sources of support.

Gifts of mentoring

567 The mentors who developed a wider appreciation of issues relating to teaching and 568 learning through the interactions with their mentees recognised what Kamvounias et $569 a$ al., (2008) referred to as the "gifts" of mentoring, indicating the mutually beneficial 570 nature of mentoring relationships:

571

'I've found it to be a really valuable experience too as a mentor, I've really enjoyed it and it's nice to be able to help somebody in the way that you may or may not have been helped in the past. So that I think is quite useful.' Mentor 5

There was a sense that such benefits were unanticipated, perhaps indicating a limited perception of mentoring as uni-directional, only of benefit to the newcomer (Donnelly and McSweeney, 2010). It could also imply the perception held by the mentor, mentee or both, that the mentoring aspect of the taught programme was an additional burden. Indeed, this was a position noted by a recent completer:

"Yes, I think a lot of people were happy for me to knock on their door and ask them very straightforward questions because I think they'd been there before, but it's a burden on them and it's a waste of their time." Mentor 8 
This is perhaps an unspoken concern of mentors and could have resulted in the tendency, whereby, if the new lecturer appeared to be coping, they were left to develop their practice independently.

'Basically people are left to get on with it and I think intervention is taken if things start to go wrong, and I've no evidence at all that that's the case, so I think it's going fine and I think what you have to do is let people get on, if they're doing a good job you need to let them get on and do a good job.' Mentor 9 '[Learning to teach] it's immersive, it's "Get in there," it's "Do it", it's "Contact people who are doing things that..." If you want to try and develop a new practical class, go and speak to this person who's done something like that.' Mentor 2

Equally, mentees were concerned about giving the impression that they were not coping or did not know what they were doing. These perspectives could limit the potential for learning and development, arguably leading mentoring relationships to stagnate or falter. However, the approaches suggested above by mentors to create learning opportunities for new lecturers through everyday practices and interactions at a school level could partly challenge this burdensome perception.

\section{Developing sustainable mentoring relationships}

Findings showed that mentoring relationships developed organically, due to factors such as individuals' experience, school support, and the perceived benefits of mentoring. Given the connection between the taught programme and mentoring, mentors perceived it as their remit to support new lecturers to develop their teaching. Indeed, whilst one mentor recognised the importance of their role in respect of this programme, they made a distinction between the perceived contributions they could make to different aspects of a new lecturer's role:

'Having a mentor is I think quite crucial, I think you do need somebody to do some of the more sort of complex questions about approaches to teaching, you know, those bigger discussions that you can have with somebody and research 

as well because that's equally important. But also you do need a named person to go to for all the really dull and boring details that you do actually need to learn.' Mentor 5

This mentor perceived their role as functional, primarily assisting their mentee in developing their teaching. This narrow conception meant that rather than supporting the new lecturer to holistically reflect on and develop their role, they concentrated solely on teaching. This is an interesting standpoint; it does not reflect the complexity of the lecturing role that encompasses a growing remit of research, teaching and administrative activities (Adcroft and Taylor, 2009; Smith, 2010). Instead it implies a perceived fragmentation in the different aspects of the role of being a university lecturer. Given that new lecturers are recognised as struggling to reconcile the breadth of their responsibilities this is not a useful position for a mentor to adopt.

The teaching programme lasted one academic year, with a mentor expected to support their mentee during this time. Explicit responsibilities were allocated to the mentor with respect to the first module of the course. As this coincides with the busiest period for most new lecturers in terms of adapting to their role, we observed the greatest number of mentor-mentee interactions occurred then. Further analysis indicated that interactions with mentors decreased over the academic year. This appeared to have implications on the use of alternate networks of support the new lecturers drew upon in their first year of teaching. Interactions with wider networks align with the idea of the distributed apprenticeship element of professional learning, the quality of which depends on the willingness of individuals to stimulate learning (Eraut, 2007; Knight et al., 2006). For instance, colleagues were seen as an essential network new lecturers actively sought to integrate with. The regularity of use was related to physical proximity (i.e. in the office next door) or perceptions that they possessed relevant knowledge:

'There's a certain amount of things you need to know beforehand and you actually learn it when you get to the point where you need to use it and when you've got supportive colleagues around you, it's great because you realise you're a bit stuck and out of your depth and you can ask them and then they help you.' Lecturer 8 
645 In addition, new lecturers discussed their practice with peers, former colleagues and 646 personal contacts. There was a sense in which discussing teaching with such 647 individuals 'low risk' as they were not exposing a lack of knowledge to a colleague or 648 mentor. These interactions were largely unplanned and, following Eraut (2007), 649 would be perceived as information sharing. There is a risk that the resulting 650 conversations (and the related advice) were accepted uncritically without examination 651 of underpinning assumptions or implications for their practice (Haigh, 2005). In 652 addition, there was often a sense that colleagues had limited time and, therefore, 653 interactions were restricted to 'snatched conversations' (Lecturer 13). This creates 654 the additional risk that new lecturers could spend considerable time trying to find 655 information from a number of colleagues as initially (at least) they may not know who 656 to contact for specific information (e.g. queries relating to timetabling, exams and 657 course administration).

Mentoring relationships are recognised as time-limited (Ehrich et al., 2004) so it is unsurprising that interactions reduced. However, a premature end or reduction in mentor support could leave a mentee with either a false sense of professional confidence, or more likely, struggling to address new challenges as they arise. This is an important consideration with respect to the cycle through which university teaching operates. Initially teaching and student support is the focus of lecturers' 665 attention, followed by a period of examination and quality assurance. The second half 666 of the teaching programme for new lecturers considers academic practice more widely. 667 Reduced interactions may mean they have limited opportunity to contextualise and 668 clarify this knowledge at the site at which it will be practiced. Although they may 669 continue to discuss their changing practice with colleagues, peers or personal contacts, 670 members of each of these groups can hold particular values, ideas or beliefs relating 671 to teaching and learning which, due to the informal nature of the interactions with 672 new lecturers, may not be examined in relation to the resulting advice and guidance 673 (Eraut, 2007; Haigh, 2005). 
Teaching development programmes are central to the professionalisation of university teaching, with mentors performing an essential role in assisting new lecturers to contextualise their practice. Although we report on a small-scale study based in one UK University, we provide insights into a relatively under-researched area within the field of academic development. Our study problematized the contribution mentors can make to the development of new lecturers and considered actions that may support new lecturers emerging practice.

Factors such as the choice of a mentor and mentor's experience as a lecturer emerged as impacting mentoring relationships and in turn professional learning. The significance of mentor choice is somewhat underplayed, particularly with respect to the guidance new lecturers received in selecting a mentor. As our data demonstrates, who becomes a mentor impacts the support received, with factors such as the mentors proximity, experience and knowledge of a schools' practice and procedures determining the guidance they are able to provide. We have to question whether a recent completer of the teaching qualification would be able to fulfil actions such as advocacy or protection to the same extent as a more established colleague. Equally, an established lecturer from the same school in relation to one of similar experience but from a different school to the one in which the mentee is based. Therefore at a fundamental level the choice of mentor can have a clear impact on the success of a relationship and the level of professional learning that may take place.

Differing conceptions of mentoring were evident, with most mentors perceiving mentoring as uni-directional, representing an additional role to be accommodated alongside already busy workloads and needs of both mentor and mentee. These factors lead to the emergence of situations whereby either mentees wanted to convey a perception of coping or, alternatively, of mentors assuming that unless they had evidence to the contrary their mentee was successfully performing their role. This impacted on the quality of mentoring relationships, and could also lead to a reliance on other forms of support. This situation may be alleviated through formal recognition of the role the mentor is performing. Indeed, in studies where institutional recognition is forthcoming (e.g. through time allocations or connections 
with mechanisms for continuing professional development) (e.g. Barkham, 2005) mentoring relationships were characterised by developmental milestones, regular meetings, and benefits regularly been reported for both parties. These mentoring relationships also appear to have lasted longer than those observed within this study, progressing through a number of clear stages (e.g. initiation, cultivation, separation and redefinition), with roles such as advocacy and protections performed, and professional benefits experienced by both parties (Kram, 1983; Barkham, 2005). Although such benefits were recorded, with mentoring cited as creating opportunities for local discussions around teaching and learning, these were noted in only a minority of cases. It is proposed that formal recognition both with respect to the process of mentoring, and also within individuals' workloads, may result in more productive and longer-lasting mentoring relationships. In order to achieve this, support from university managers (e.g. head of schools / deans) would be essential, particularly with respect to formalising mentoring relationships. Such moves may be timely, given the moves within the UK through the UKPSF to further recognise and accredit the teaching experiences of more established lecturers, and provide a career trajectory for those with an explicit interest in teaching rather than disciplinary-based research (HEA, 2011).

Recognising mentoring relationships would ensure dedicated time is allocated for mentoring and situations for professional learning are fostered. It is not to say these were not present in the study university, rather it would have ensured parity. Interactions between the mentor and new lecturer also need to encourage critical interrogation and reflection on the practice of both parties to enhance individuals' awareness of the values, beliefs and concepts that underpin practice (Kreber, 1999; Trowler and Cooper, 2002). These were actions that were observed to be challenging, with the tendency for functional or practical discussions to prevail. This is where the integration of critical incidents or raising awareness of Haigh's (2005) idea of 'learningful conversations' may prove advantageous, as both could be used to support new lecturers to understand how actions taken in practice promote student learning. 
739 Although wider support networks have an important role to play, the contribution

740 made to professional learning needs to be framed in relation to the nature of the

741 interactions that are taking place. They provide a valuable source of informal advice

742 and guidance. Regular interactions within these wider networks also assist new

743 lecturers to develop a sense of belonging (Warhurst, 2008). We need to enhance new

744 lecturers awareness of using this wider networks to stimulate professional learning

745 and provide mechanisms for meaningful engagement with them. To date, this is an

746 area that although of growing prominence (e.g. Boud and Brew, 2012; Reintes and

747 Kichin, 2014) has not been fully explored with respect to promoting academic

748 development, which is an area worthy of further consideration to identify how they

749 can be used to promote professional learning.

751 In this study, we have captured data on interactions between new lecturers, their

752 mentors, and wider support networks over one academic year. Within the context of

753 this study the majority of the mentoring relationships were coming to an end toward

754 the end of the academic year. As we have noted, in business, schools and other

755 settings where mentoring is a feature of professional development, mentoring

756 relationships may be sustained until a natural end is reached (Kram, 1983; Ragins and

757 Cotton, 1999). We recommend further research into mentoring relationships for those

758 new to lecturing which examines more specifically the instigation, development and

759 termination of these relationships. Such research also needs to consider more

760 explicitly interactions with wider support networks, particularly with respect to the

761 learning they promote. Likewise, it would need to heed the context in which many

762 new lecturers are working, in that as well as undertaking a teaching qualification they

763 will be balancing their research commitments and potentially other administrative

764 roles. As mentoring may be specifically tied to the teaching qualification, the

765 mechanisms of support for the wider aspects of a new lecturer's role could provide

766 valuable insights into how mentoring could be integrated more holistically into the

767 professional development for new academics over the longer term. 

This research was supported with a grant from the Pedagogic Research Institute \& Observatory, Plymouth University. We thank all the new lecturers and mentors for their participation in this study.

\section{References}

Adcroft, A. and Taylor, D. 2009. Developing a conceptual model for career support for new academics. International Journal of Teaching and Learning in Higher Education, 22, (3), 287-298.

Achinstein, B. and Athanases, S.Z. 2006. Mentors in the making: developing new leaders for mew teachers. New York: Teachers College Press.

Bamber, V. 2008. Evaluating lecturer development programmes: received wisdom or self knowledge? International Journal for Academic Development, 13, (2), 107-116.

Barkham, J. 2005. Reflections and interpretations on life in academia: a mentee speaks. Mentoring \& Tutoring: Partnership in Learning, 13, (3), 331-344.

Boud, D. \& Brew, A. (2012). Reconceptualising academic work and professional practice: implications for academic development. International Journal for Academic Development, 18 (3), 201-221.

Boud, D. 1999. Situating academic development in professional work: Using peer learning. International Journal for Academic Development, 4, (1), 3-10.

Boyd, P., and Harris, K. 2010. Becoming a university lecturer in teacher education: expert schoolteachers reconstructing their pedagogy and identity. Professional Development in Education, 36, (1), 9-25.

Calderhead, J. 1981. Stimulated recall: a method for research on teaching. British Journal of Educational Psychology, 51, (2), 211-217.

Donnelly, R., and McSweeney, F. 2010. From humble beginnings: evolving mentoring within professional development for academic staff. Professional Development in Education, 37, (2), 259-274. 
797 Ehrich, L. C., Hansford, B., and Tennent, L. 2004. Formal Mentoring Programs in 798 Education and Other Professions: A Review of the Literature. Educational 799 Administration Quarterly, 40, (4), 518-540.

800 Eraut, M. 2004. Informal learning in the workplace. Studies in Continuing Education, $80126,(2), 247-273$.

802 Eraut, M. 2007. Learning from other people in the workplace. Oxford Review of 803 Education, 33, (4), 403-422.

804 Ewing, R., Freeman, M., Barrie, S., Bell, A., O’ Connor, D., Waugh, F., and Sykes, C. 805 2008. Building community in academic settings: the importance of flexibility in a 806 structured mentoring program. Mentoring \& Tutoring: Partnership in Learning, 16, 807 (3) 294-310.

808 Gehrke, N. 1998. Toward a deinfiation of mentoring. Theory into Practice, 45, 809 (2), 190-194.

810 Gibbs, G. (2010). Dimensions of Quality. York: Higher Education Academy. 811 Available from: https://www.heacademy.ac.uk/sites/default/files/doq_summary.pdf 812 [last accessed 1 October, 2014]

813 Gosling, D. (2009). A new approach to peer review of teaching. In: D. Gosling \& K 814 Mason O'Connor (eds.), Beyond the Peer Observation of Teaching: 7-15. SEDA, 815 London.

816 Gosling, D. (2010). Professional development for new staff - how mandatory is your 817 post graduate certificate? Educational Developments, 11:1-4.

818 Green, W. and Myatt, P. 2011. Telling tales: a narrative research study of the 819 experiences of new international academic staff at an Australian university. 820 International Journal for Academic Development, 16, (1), 33-44.

821 Hagger, H., Burn, K., Mutton, T., and Brindley, S. 2008. Practice makes perfect? 822 Learning to learn as a teacher. Oxford Review of Education, 34, (2), 159-178. 823

824 Hagger, H. \& McIntyre D. 2006. Learning teaching from teachers. Maidenhead: 825 Open University. 
827 Haigh, N. 2005. Everyday conversation as a context for professional learning and development. International Journal for Academic Development, 10, (1), 3-16.

829 Hammersley-Fletcher, L., and Orsmond, P. 2005. Reflecting on reflective practices 830 within peer observation. Studies in Higher Education, 30, (2), 213-224.

831 HEA. 2011. The UK Professional Standards Framework for teaching and supporting 832 learning in higher education.

833 http://www.heacademy.ac.uk/assets/documents/ukpsf/ukpsf.pdf

834 Hobson, A.J., Asheby, A., Malderez, A. and Tomlinson, P.D. 2009. Mentoring 835 beginning teachers: what we know and what we don't know. Teaching and Teacher 836 Education, 25, (10). 207-216.

837 Holsti, O. 1969. Content analysis for the social sciences and humanities. Don 838 Mills:Addison-Wesley.

839 Hudson, P. 2013. Mentoring as professional development: 'growth for both' mentor 840 and mentee. Professional Development in Education, 39, (5), 771-783.

841

842 Kahn, P., Young, R., Grace, S., Pilkington, R., Rush, L., Tomkinson, B., and Willis, I.

843 2008. Theory and legitimacy in professional education: a practitioner review of 844 reflective processes within programmes for new academic staff. International Journal 845 for Academic Development, 13, (3), 161-173.

846 Kamvounias, P., McGrath-Champ, S., and Yip, J. 2008. Gifts in mentoring: mentees' 847 reflections on an academic development program. International Journal for Academic 848 Development, 13, (1), 17-25.

849 Kandlbinder, P., and Peseta, T. 2009. Key concepts in postgraduate certificates in 850 higher education teaching and learning in Australasia and the United Kingdom.

851 International Journal for Academic Development, 14, (1), 19-31.

852 Knight, P., Tait, J. and Yorke, M. 2006. The professional learning of teachers in 853 higher education. Studies in Higher Education, 31, (3), 319-339. 
854 Knight, P. T., and Trowler, P. R. 1999. It Takes a Village to Raise a Child: mentoring 855 and the socialisation of new entrants to the academic professions. Mentoring \& 856 Tutoring: Partnership in Learning, 7, (1), 23-34.

857 Kovacs, S., Grant, L. \& Hyland, F. (2010). A study of the use of the National Student 858 Survey to enhance the student experience in education departments. ESCalate, 859 Unviersity of Bristol.

860 Kram, K.E. 1983. Phases of the mentoring relationship. Academic of Management 861 Journal, 26, (4), 608-625.

862 Kreber, C. 1999. A course-based approach to the development of teaching863 scholarship: a case study. Teaching in Higher Education, 4, (3), 309-325.

864 Langdon, F. 2011. Shifting perception and practice: New Zealand beginning teacher 865 induction and mentoring as a pathway to expertise. Professional Development in 866 Education, 37, 2, 241-258.

867 Noe, R.A. 1988. An investigation of the determinants of successful assigned 868 mentoring relationships. Personnel Psycology, 41, (3), 457-479.

869 Parsons, D., Hill, I., Holland, J. and Willis, D. (2012). Impact of teaching 870 development programmes in higher education. York: Higher Education Academy.

871 Quinn, L. (2012). Understanding resistance: an analysis of discourses in academic 872 staff development. Studies in Higher Education, 37: 69-83.

873 Ragins, B.R. and Cotton, J.L. 1999. Mentor functions and outcomes: a comparison of 874 men and women in formal and informal mentoring relationships. Journal of Applied 875 Psycology, 84, (4), 529-550.

876 Remmik, M., Karm, M., Haamer, A., and Lepp, L. 2011. Early-career academics 877 learning in academic communities. International Journal for Academic Development, 878 16, (3), 187-199.

879 Rienties, B., Brower, N. and Lygo-Baker, S (2013). The effects of on-line 880 professionald evelopment on higher educarion teachers' beliefs and intentions 881 towards leanring facilitation and technology. Teaching and Teacher Education, 29, $882 \quad 122-131$. 
883 Smith, J. 2010. Forging identities: the experiences of probationary lecturers in the UK.

884 Studies in Higher Education, 35, (5), 577-591.

885 Trigwell, K. \& Prosser, M. 1996. Changing approaches to teaching: a relational;

886 perspective. Studies in Higher Education, 21, (3), 275-84.

887 Tripp, D. 1993. Critical Incidents in Teaching: developing professional judgement.

888 London: Routledge.

889 Trowler, P. and Cooper, A. 2002. Teaching and Learning Regimes: Implicit theories

890 and recurrent practices in the enhancement of teaching and learning through

891 educational development programmes. Higher Education Research \& Development,

$892 \quad 21,(3), 221-240$.

893 Turner, R., Huang, R. \& Poverjuc, O. (2012). Challenging Times: An Exploration of

894 The Diverse Experiences of Lecturers Learning to Teach in UK Higher

895 Education. Paper presented at the European Conference on Educational Research,

896 University of Cadiz, Cadiz, Spain 18-21 ${ }^{\text {st }}$ September 2012.

897 Turner, N., Oliver, M., McKenna, C., Smith, H., Deepwell, F., and Shrives, L. (2013).

898 Measuring the impact of the UK Professional Standards Framework for teaching and 899 supporting learning. York: HEA.

900 Warhurst, R. P. 2006. "We Really Felt Part of Something": Participatory learning

901 among peers within a university teaching-development community of practice.

902 International Journal for Academic Development, 11, (2), 111-122.

903 Warhurst, R. P. 2008. 'Cigars on the flight-deck': new lecturers' participatory

904 learning within workplace communities of practice. Studies in Higher Education, 33,

905 (4), 453-467.

906 Wisdom, J., Lea, J. \& Parker, P. (2013) A short history of SEDA.

907 http://www.seda.ac.uk/resources/files/SEDA\%20Short\%20History_WEB\%20v2.pdf

908 Accessed $13^{\text {th }}$ October 2014.

909

910

911 
912

913

914 